\title{
Ventilation revealed by the observation of dissolved oxygen concentration south of the Kuroshio Extension during 2012-2013
}

\author{
Akira Nagano ${ }^{1}$ ( $\cdot$ Toshio Suga $^{1,2} \cdot$ Yoshimi Kawai $^{1} \cdot$ Masahide Wakita $^{3} \cdot$ \\ Kazuyuki Uehara $^{4} \cdot$ Kyoko Taniguchi $^{1}$
}

Received: 25 December 2014 / Revised: 15 May 2016 / Accepted: 18 June 2016 / Published online: 12 July 2016 (c) The Author(s) 2016. This article is published with open access at Springerlink.com

\begin{abstract}
From the moored buoy observation at $33.9^{\circ} \mathrm{N}$, $144.9^{\circ} \mathrm{E}$ south of the Kuroshio Extension (KE), we obtained Eulerian time series of dissolved oxygen concentration (DO) at 200, 400, and $600 \mathrm{~m}$ depths from June 2012 to March 2013. We observed ventilation by meso- and submesoscale processes that transport water southward across the KE jet. First, the cyclonic mesoscale eddy in June 2012 substantially depressed DO at depths of 400 and $600 \mathrm{~m}$ but maintained DO at $200 \mathrm{~m}$, suggesting near-surface lateral transport of high-DO water derived from the north of the KE. Second, subduction of high-DO ( $\left.>230 \mu \mathrm{mol} \mathrm{kg}{ }^{-1}\right)$ water to a depth of $600 \mathrm{~m}$ was observed from early February to March 2013, associated with a mesoscale/submesoscale meandering of the KE jet. In mid-March 2013, shipboard hydrographic data were collected where the water mass at the mooring site would be advected by the eastward current on the southern flank of the KE. Based on these data, the subduction event was identified as an intrusion of an anomalously thick water mass from approximately 400-900 dbar. Ventilation of the subtropical mode water at a depth of $200 \mathrm{~m}$ around a subsurface DO maximum layer was detected as a rapid rise in DO in January
\end{abstract}

Akira Nagano

nagano@jamstec.go.jp

1 Research and Development Center for Global Change, Japan Agency for Marine-Earth Science and Technology, 2-15 Natsushima-cho, Yokosuka, Kanagawa 237-0061, Japan

2 Graduate School of Science, Tohoku University, 6-3 Aramkai-aza-aoba, Aoba-ku, Sendai 980-8578, Japan

3 Mutsu Institute for Oceanography, Japan Agency for MarineEarth Science and Technology, 690 Kitasekine, Sekine, Mutsu, Aomori 035-0022, Japan

4 School of Marine Science and Technology, Tokai University, 3-20-1 Orido, Shimizu-ku, Shimizu 424-8610, Japan
2013. This occurred after a significant seasonal decrease in DO at a rate of $-0.130 \pm 0.007 \mu \mathrm{mol} \mathrm{kg}{ }^{-1}$ day $^{-1}$ from July to December 2012.

Keywords Kuroshio Extension · Dissolved oxygen concentration $\cdot$ Ventilation $\cdot$ Subduction $\cdot$ Mesoscale eddy

\section{Introduction}

Water masses formed in the winter mixed layer around the Kuroshio Extension (KE) and to its north are exposed to the atmosphere and are nearly saturated with oxygen. After being isolated from the atmosphere, the water masses with high dissolved oxygen concentration (DO) are subducted to the main thermocline and extend southwestward on isopycnal surfaces along the North Pacific subtropical gyre (e.g., Reid 1997; Suga et al. 2008). Throughout this process, called ventilation, the influence of the atmospheric conditions spreads to the subsurface layer within the subtropical gyre.

The climatological tongue-like structure of high DO across the $\mathrm{KE}$ is considered to be the averaged traces of smaller-scale subducted high-DO water masses. Focusing on the KE region and the region to the south, Measures et al. (2006) and Oka et al. (2009) reported mesoscale/submesoscale water masses with high DO in the main pycnocline to the south of the KE jet. Oka et al. (2009) described a high-DO patchy water mass 150 dbar thick and $40 \mathrm{~km}$ in diameter in the layer centered at the potential density $\left(\sigma_{\theta}\right)$ surface of $26.37 \mathrm{~kg} \mathrm{~m}^{-3}$ ( hereafter expressed as $26.37 \sigma_{\theta}$ ) at a depth of approximately $500 \mathrm{dbar}$. The mesoscale/submesoscale water masses observed in subsurface layers would be subducted from areas north of the KE jet, where outcropping of water with potential density equivalent to 


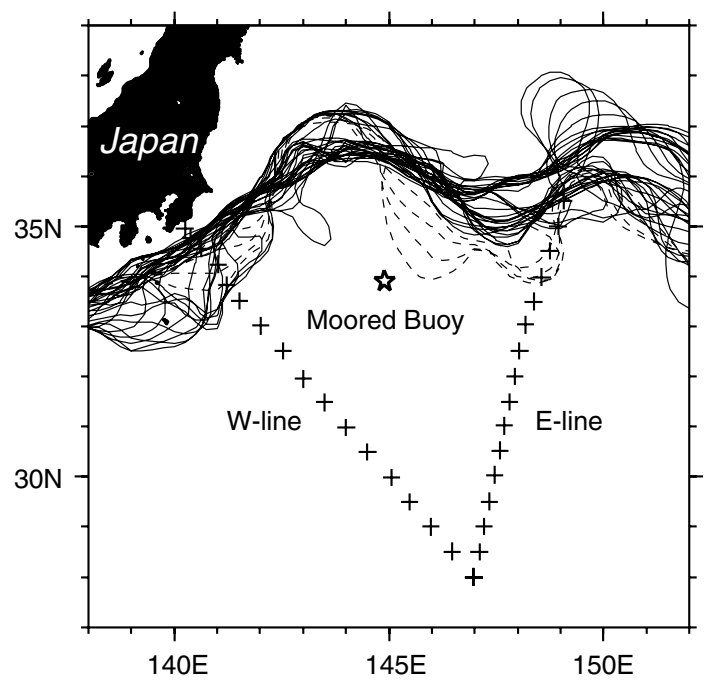

Fig. 1 Locations of a mooring site of the K-TRITON buoy (star) and $\mathrm{CTDO}_{2}$ stations by the R/V Ryofu-maru (crosses). Weekly KE paths from June 27, 2012, to March 6, 2013, are indicated by the absolute SSH contour of $100 \mathrm{~cm}$. KE paths after February 13, 2013, are shown by dashed contours, and others by solid contours. SSH data were obtained from Archiving, Validation and Interpretation of Satellite Oceanographic (AVISO) data

that of the patchy water masses occurs in winter. However, there is no direct evidence of such cross-frontal subduction in the KE region.

Various researchers have examined characteristics of meso- or submesoscale DO variations south of the KE jet. Using an Argo float deployed to the south of the KE, Sukigara et al. (2011) obtained a DO time series down to a depth of $1000 \mathrm{~m}$ at 5-day intervals from March to July 2006. Using quasi-Lagrangian observations, they illustrated the variability of DO in the ventilated water mass trapped within an anticyclonic mesoscale eddy. Changes in DO within water masses result from physical and biogeochemical processes such as mixing with surrounding water and remineralization of organic matter. A deeper understanding of the spatiotemporal DO variation will provide insight into the ventilation of water masses into subsurface layers and their subsequent circulations.

To assess ventilation by subduction across the KE jet, a high-frequency time series observation of DO was conducted in 2012 by deploying a moored buoy at a station south of the jet (star in Fig. 1). This was part of a collaborative research program titled "Hot Spot in Climate System: Coupled OceanAtmosphere Variability over Monsoonal Asia due to Contiguousness between the Tropical Warmness and Arctic Coolness" (Nakamura et al. 2015). Based on this Eulerian time series observation, we aim to describe the DO variations near the KE and to obtain direct evidence of cross-frontal subduction and knowledge about how subducted water is transported across the KE jet through mesoscale/submesoscale processes.
We observed DO variations resulting from isopycnal uplift and lateral water transport by cyclonic eddies, a seasonal decrease in DO and its rapid rise to near saturation, and southward mesoscale/submesoscale water mass subduction across the KE. In this study, we demonstrate the variation in DO using Eulerian DO time series and conductivity-temperature-depth-oxygen $\left(\mathrm{CTDO}_{2}\right)$ sections collected by a research vessel. Our observations and data are presented in Sect. 2. In Sect. 3, we illustrate the variation in DO due to the above-mentioned three factors using the DO time series and shipboard $\mathrm{CTDO}_{2}$ data. Our results are summarized in Sect. 4.

\section{Observations and data}

\subsection{Moored buoy observation}

On June 22, 2012, we deployed the Kuroshio-Triangle Trans-Ocean buoy Network (K-TRITON) buoy at $33.9^{\circ} \mathrm{N}$, $144.9^{\circ} \mathrm{E}$ (Fig. 1) using the R/V Mirai of the Japan Agency for Marine-Earth Science and Technology (JAMSTEC). A diagram of the buoy mooring system is shown in Fig. 2. The design of the buoy system was based primarily on the m-TRITON buoy system (Ueki et al. 2010) developed by JAMSTEC, and modified based on the Kuroshio Extension Observatory buoy (Cronin et al. 2008) developed by the US National Oceanic and Atmospheric Administration (NOAA). To ensure successful deployment of the buoy in strong currents such as the KE, it was moored with a 3.8-ton anchor. The load on the line from the current was mitigated using slack-line mooring with a large scope ratio (1.53) to a depth of $5746 \mathrm{~m}$ and fairing down to a depth of $190 \mathrm{~m}$. The buoy was able to move within a radius of approximately $7 \mathrm{~km}$ from the mooring point. CTD, DO, conductivity-temperature (CT) sensors, and a current meter were installed on the subsurface line. A suite of meteorological sensors was installed on the buoy tower.

The buoy was initially deployed for a 1-year observation, but drifted due to an unexpected mooring break on March 8, 2013. The drifting buoy was recovered by the R/V Mirai soon afterward. The sensors attached to the mooring line were recovered by the JAMSTEC R/V Kaiyo on July 7, 2013, after lying on the seabed for 3 months. We examined DO and CTD data obtained over approximately 10 months from early summer (June 22, 2012) to late winter (March 7, 2013).

We attached RINKO I optical DO sensors (JFE Advantech Co., Ltd., Nishinomiya, Japan) to the mooring line at depths of 200, 400, and $600 \mathrm{~m}$ (marked by red, green, and blue rectangles in Fig. 2, respectively). Due to the lateral movement of the buoy, the 200- and 600-m sensors were displaced vertically over ranges of 190-203 
Fig. 2 Mooring diagram of the K-TRITON buoy deployed at $33.9^{\circ} \mathrm{N}, 144.9^{\circ} \mathrm{E}$ (star in Fig. 1). DO sensors at depths of 200 , 400 , and $600 \mathrm{~m}$ are shown as red, green, and blue rectangles, respectively. Other sensors are shown as black rectangles. Colors of DO sensors correspond to the lines in Fig. 3

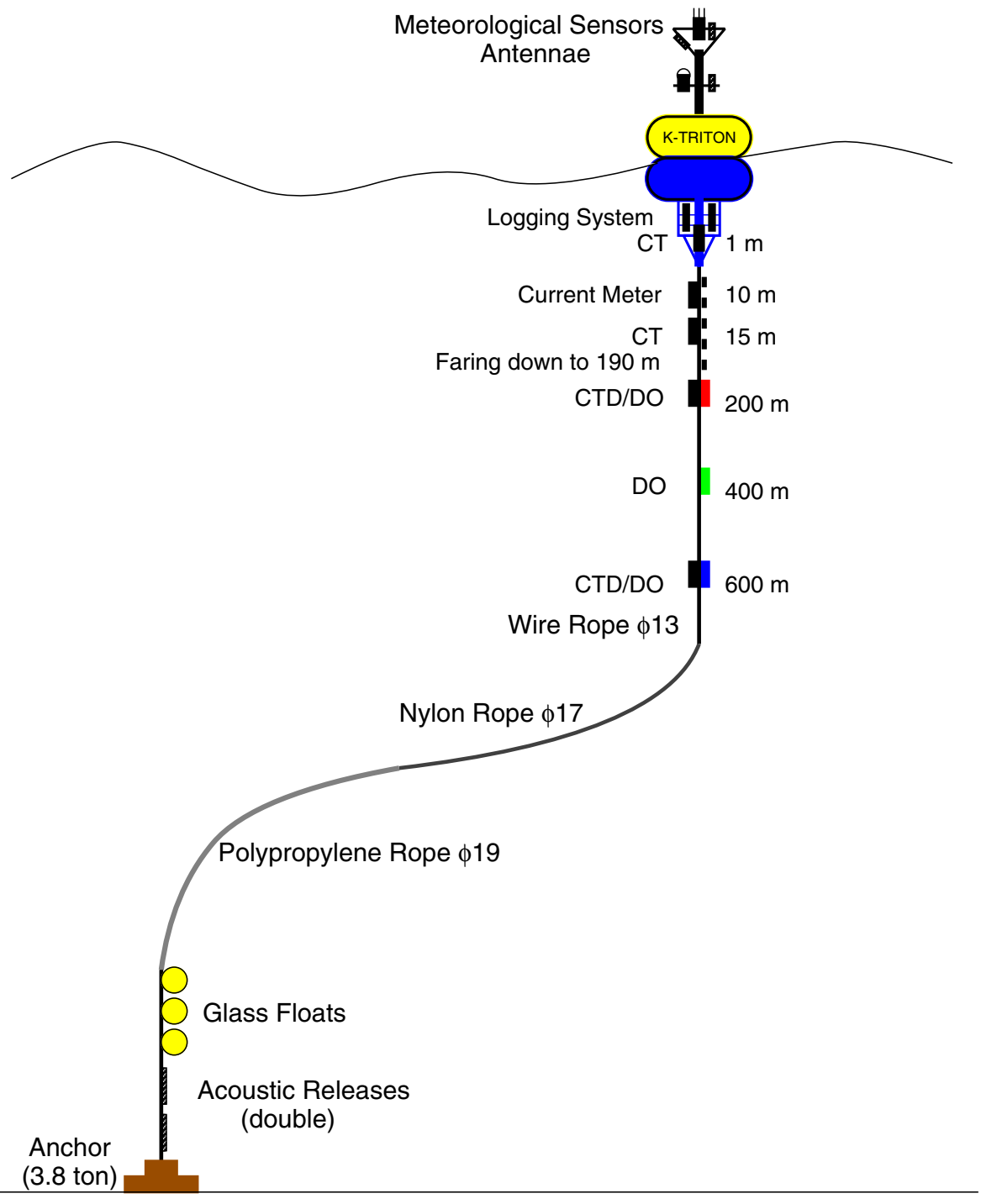

and 520-605 dbar, respectively. Thus, to obtain meaningful descriptions of DO variations, in addition to referring to the nominal sensor depths, it is necessary to address the potential density time series based on the CTD data. To offset initial sensor drift, we kept the sensors operating for approximately 3 weeks before deployment. DO saturation percentage and temperature were measured at intervals of $30 \mathrm{~min}$, and their daily mean values were used. The accuracy of saturation percentage and temperature provided by the manufacturer are $2 \%$ of full-scale range (0-200\%) and $0.02{ }^{\circ} \mathrm{C}$, respectively. To estimate oxygen solubility, we adopted the polynomial prepared by García and Gordon (1992) and used temperature data obtained from built-in RINKO I thermometers and salinity data from the SBE 37 CTD system (Sea-Bird Electronics, Bellevue, WA, USA) at depths of 200 and $600 \mathrm{~m}$. The oxygen solubility at a depth of $400 \mathrm{~m}$ was calculated using the RINKO I temperature values and interpolated salinity values based on the data at depths of 200 and $600 \mathrm{~m}$. Multiplying the saturation percentage by oxygen solubility, we obtained DO values in the unit of $\mu \mathrm{mol} \mathrm{kg}-1$. The nominal accuracy of DO for the present measurements is equivalent to or better than $11 \mu$ mol kg-1 This is smaller than the variation ranges $(>30 \mu$ mol kg-1), as described in Sect. 3 .

\subsection{Shipboard observation}

In early July and early December 2012, $\mathrm{CTDO}_{2}$ data were collected aboard the R/V Ryofu-maru operated by the Japan Meteorological Agency (JMA). The data were obtained to depths over 2000 dbar in the KE region using an SBE 911plus CTD system (Sea-Bird Electronics) and a RINKO III (JFE Advantech) with Niskin bottles mounted on a SBE 32 Carousel water sampler. Immediately after the buoy observation (mid-March 2013), $\mathrm{CTDO}_{2}$ data were collected aboard the vessel. The observation line extends 
southeastward from the coast of Boso Peninsula to $28^{\circ} \mathrm{N}$, $147^{\circ} \mathrm{E}$ (hereafter referred to as the $\mathrm{W}$-line), and then turns north-northeastward (E-line) (Fig. 1). The $\mathrm{CTDO}_{2}$ casts were performed at latitudinal intervals of $0.5^{\circ}$, enabling detection of mesoscale features. The accuracy of the CTD temperature and conductivity data are $0.001{ }^{\circ} \mathrm{C}$ and $0.0003 \mathrm{~S} \mathrm{~m}^{-1}$, respectively. CTD salinity values were corrected with bottle salinity data measured with a laboratory salinometer, Guildline 8400B Autosal (Guildline Instruments Limited, Ontario Canada). The accuracy of the salinity data, measured as the root-mean-square (rms) difference between the bottle and corrected CTD salinity values, is 0.0133 . The RINKO III DO values were corrected with bottle DO data measured with an automatic recording titrator. The accuracy of the DO data, based on the rms difference between bottle and corrected RINKO III DO values, is $4.99 \mu \mathrm{mol} \mathrm{kg}-1$.

\section{Results and discussion}

\subsection{Lateral water transport by mesoscale eddy}

As illustrated by the solid contours in Fig. 1, the KE was at an almost constant distance from the mooring buoy station (star) until February 6, 2013. During most of the observation period, potential density at depths of $200 \mathrm{~m}$ (red dotted line in Fig. 3a) and $600 \mathrm{~m}$ (blue dotted line) varied within $25.0-25.4 \sigma_{\theta}$ and $26.0-26.6 \sigma_{\theta}$, respectively. In June and September of 2012, potential density at depths of 200 and $600 \mathrm{~m}$ was considerable larger than that during the other periods. On these occasions, cyclonic mesoscale eddies were denoted by minimal sea surface height (SSH) centered around $33.8^{\circ} \mathrm{N}, 145.0^{\circ} \mathrm{E}$ (Fig. $4 \mathrm{a}$ ) and $33.8^{\circ} \mathrm{N}, 144.5^{\circ} \mathrm{E}$ (Fig. 4c) around the buoy station. As a result, the 200- and 600-m sensors were outside the above-mentioned density ranges due to shoaling of the isopycnal surfaces.

When the central part of the cyclonic eddy passed near the buoy station in June 2012 (downward arrow in Fig. 3a), DO was considerably lower at depths of 400 and $600 \mathrm{~m}$ (green and blue solid lines in Fig. 3a) but not at $200 \mathrm{~m}$ (red solid line). In this case, the CTD sensor at $200 \mathrm{~m}$ recorded very cold $\left(\sim 9{ }^{\circ} \mathrm{C}\right)$ and fresh $(\sim 34.1)$ water. Presumably, this water originated north of the $\mathrm{KE}$ at a depth of approximately $200 \mathrm{dbar}$ (e.g., Figs. $6 \mathrm{~b}$ and $7 \mathrm{~b}$ in Nagano et al. 2014) and could contain a larger amount of oxygen than that on the same isopycnal surface south of the KE. In early July, a few weeks after the DO depressions at 400 and $600 \mathrm{~m}$, the eastern limb of the cyclonic eddy passed the buoy station (Fig. 4b), and DO reached a minimum at $200 \mathrm{~m}$. With the cyclonic eddy passage in September 2012, DO was reduced at all depths.

The cyclonic mesoscale eddy in June 2012 was much stronger than that in September 2012. This is indicated
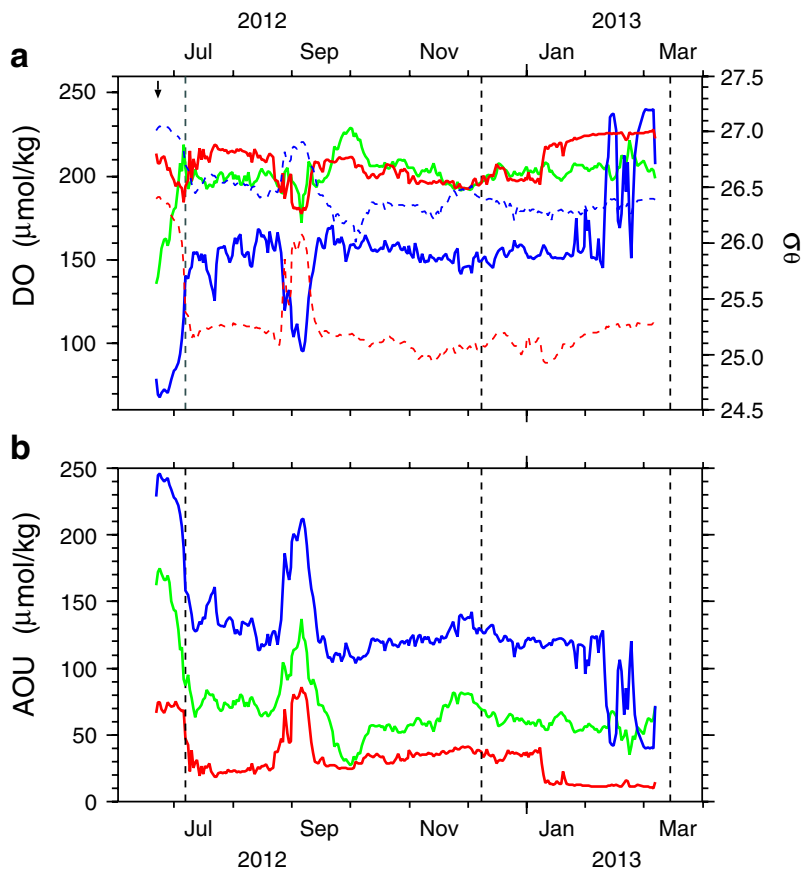

Fig. 3 a Potential density $\sigma_{\theta}$ at depths of $200 \mathrm{~m}$ (red dotted line) and $600 \mathrm{~m}$ (blue dotted line); and DO at depths of $200 \mathrm{~m}$ (red solid line), $400 \mathrm{~m}$ (green solid line), and $600 \mathrm{~m}$ (blue solid line) at the moored buoy station. The downward arrow indicates no DO depression despite the passage of a cyclonic eddy near the buoy station. b AOU at depths of $200 \mathrm{~m}$ (red solid line), $400 \mathrm{~m}$ (green solid line), and $600 \mathrm{~m}$ (blue solid line). Vertical dashed lines denote $\mathrm{CTDO}_{2}$ observations conducted aboard the R/V Ryofu-maru

by the lower SSH at the eddy center on June $20(\sim 70 \mathrm{~cm})$ (Fig. 4a) than on September $5(\sim 110 \mathrm{~cm})$ (Fig. 4c). The local Rossby number $U / \beta R^{2}$, where $U$ is the eddy current speed derived from $\mathrm{SSH}, \beta$ is the latitudinal variation of the Coriolis parameter, and $R$ is the eddy radius [e.g., Ichikawa et al. (1995)], exceeds 10 for the eddy in June, which is more than twice that for the eddy in September. The strong cyclonic eddy in June was able to capture high-DO water within the interior of the eddy and carry it from the formation region north of the KE.

Apparent oxygen utilization (AOU), the difference between the measured and saturated DO, was higher in the deeper layers until February 12, 2013 (Fig. 3b), suggesting that the water masses were piled up in the order of older to younger. Even with the passage of the cyclonic mesoscale eddies, the structure of the chronological order below a depth of $200 \mathrm{~m}$ was undisturbed, although AOU increased by over $50 \mu \mathrm{mol} \mathrm{kg}{ }^{-1}$. Thus, the large AOU elevations, or DO depressions, at 400 and $600 \mathrm{~m}$ in June 2012 and those at all depths in September 2012 can be explained by the ascending deep low-DO (high-AOU) water by the cyclonic eddies. The high-DO water at $200 \mathrm{~m}$ in June suggests a contribution from the lateral transport of water by a 

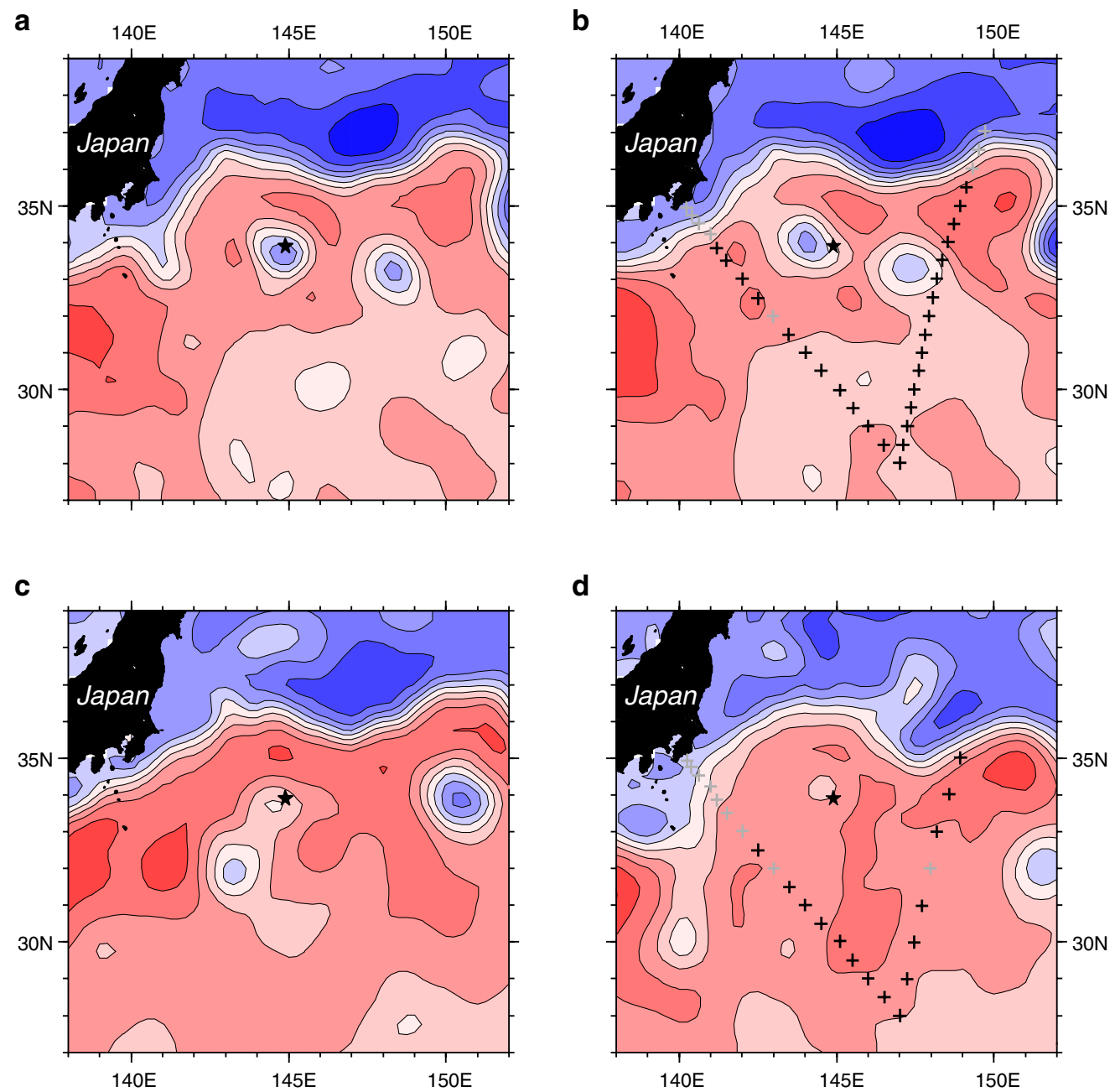

d

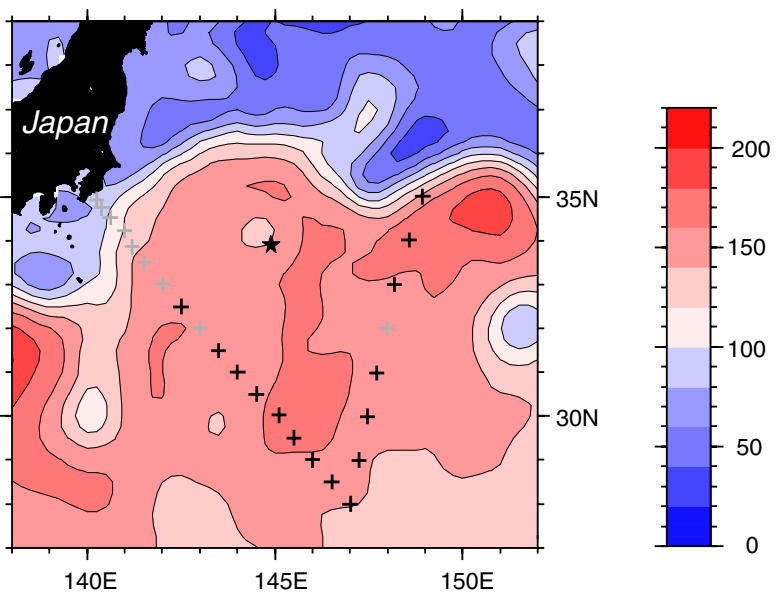

Fig. 4 Absolute SSH (cm) in the KE region on a June 20, b July 4, c September 5, and d December 5, 2012. Contour interval is $20 \mathrm{~cm}$. SSH data were derived from AVISO. A star indicates the moored

buoy station. In $\mathbf{b}$ and $\mathbf{d}, \mathrm{CTDO}_{2}$ stations where $\mathrm{AOU}$ is smaller than $30 \mu \mathrm{mol} \mathrm{kg} \mathrm{kg}^{-1}$ on an isopycnal of $25.3 \sigma_{\theta}$ are denoted by black crosses, and other stations are indicated by gray crosses

strongly nonlinear eddy just after being pinched off from the KE.

\subsection{Oxygen consumption and recovery to near saturation}

DO at a depth of $200 \mathrm{~m}$ (red solid line in Fig. 3a) dwindled from July to December 2012, except for the rapid decreases and recoveries of DO associated with the mesoscale eddies. Using a linear regression from July to December, and excluding the periods of eddy passage, the decreasing rate at $200 \mathrm{~m}$ was estimated as $-0.130 \pm 0.007 \mu$ mol $\mathrm{kg}^{-1} \mathrm{day}^{-1}$ (the error value was calculated as the rms difference from the linear regression slope). The rate of decrease is one order of magnitude greater than the error value and the $95 \%$ significance level (0.013) based on Student's $t$ test, i.e., statistically significant. During the same period, the linear trends of DO at depths of

$400 \mathrm{~m}\left(-0.011 \pm 0.014 \mu \mathrm{mol} \mathrm{kg}{ }^{-1} \mathrm{day}^{-1}\right)$ and $600 \mathrm{~m}$ $\left(-0.030 \pm 0.012 \mu \mathrm{mol} \mathrm{kg}{ }^{-1} \mathrm{day}^{-1}\right)$ were one order of magnitude smaller than that at $200 \mathrm{~m}$. Because the DO sensors were located at fixed depths below the euphotic layer, DO varied due to oxygen consumption through remineralization of organic matter, vertical isopycnal displacement, and water intrusion. Oxygen consumption through remineralization and vertical displacement of water likely caused the gradual decrease in DO at $200 \mathrm{~m}$. At depths of 400 and $600 \mathrm{~m}$, the consumption of DO through remineralization was much smaller than that at $200 \mathrm{~m}$, likely because the organic carbon flux, which enhances oxygen utilization, decreased with depth, as Suess (1980), Sarmiento and Gruber (2006), and others have illustrated.

In the early July 2012 observation (black crosses in Fig. 4b), at most of the $\mathrm{CTDO}_{2}$ stations south of the KE jet (the sharp SSH gradient), AOU lower than $30 \mu \mathrm{mol} \mathrm{kg} \mathrm{kg}^{-1}$ was recorded on the isopycnal of $25.3 \sigma_{\theta}$ deeper than the 


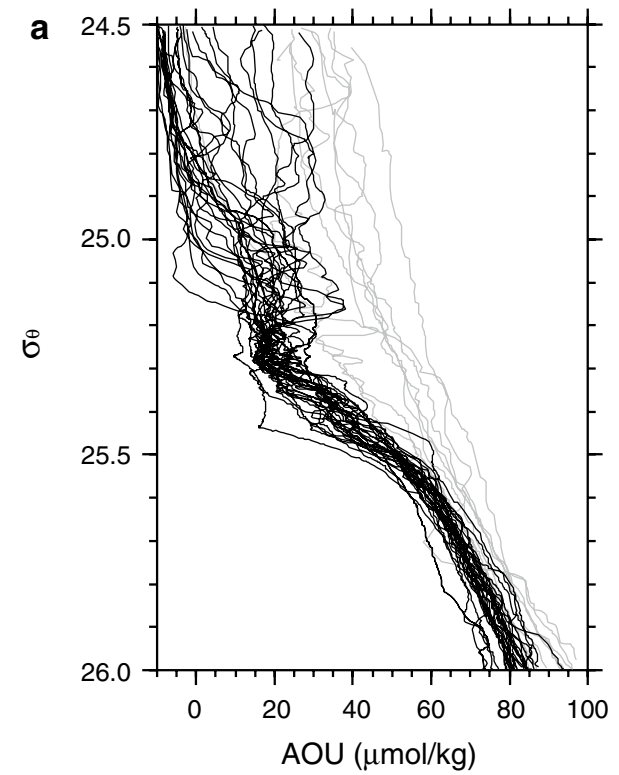

Fig. 5 Vertical profiles of a AOU and $\mathbf{b}$ PV with respect to $\sigma_{\theta}$ at the W-line and E-line in early July 2012. Profiles of AOU smaller than $30 \mu \mathrm{mol} \mathrm{kg}-1$ on an isopycnal of $25.3 \sigma_{\theta}$ are indicated by black lines,

primary DO maxima, or the shallow maximal oxygen layer, near the sea surface (Reid 1962; Sukigara et al. 2011, 2014); these profiles are shown by black lines in Fig. 5a. We calculated potential vorticity (PV) defined as

$\mathrm{PV}=-\frac{f}{\rho} \frac{\partial \sigma_{\theta}}{\partial z}$,

where $f$ is the Coriolis parameter, $\rho$ is water density, and $z$ is the upward vertical coordinate (e.g., Talley 1988; Hanawa and Talley 2001). At stations with low AOU on the isopycnal of $25.3 \sigma_{\theta}$ (black lines in Fig. 5b), the minima of PV smaller than $1.5 \times 10^{-10} \mathrm{~m}^{-1} \mathrm{~s}^{-1}$, or the cores of the subtropical mode water (STMW), were found in the isopycnal layer.

At many stations south of the KE jet in early December 2012 (black crosses in Fig. 4d), the low-AOU water existed as subsurface AOU minima on the isopycnal of approximately $25.3 \sigma_{\theta}$ (black lines in Fig. 6a). The AOU minima correspond to the layer of the secondary DO maxima between approximately 200 and $300 \mathrm{~m}$ to the south of the Kuroshio and KE (Okubo 1958; Taft 1978). Taft (1978) suggested that the secondary DO maxima were derived from the STMW. As indicated by the PV minima $\left(<1.5 \times 10^{-10} \mathrm{~m}^{-1} \mathrm{~s}^{-1}\right)$ on the isopycnal of $25.3 \sigma_{\theta}$ (Fig. 6b) at the stations marked by black crosses in Fig. 4d, the subsurface AOU minima coincide with the cores of the STMW. From early July (Fig. 5a) through early December 2012 (Fig. 6a), AOU around the isopycnal of $25.3 \sigma_{\theta}$ increased less than that in the upper layer. Using the data at the stations with $\mathrm{AOU}<30 \mu$ mol kg${ }^{-1}$ on the $25.3 \sigma_{\theta}$ surface (black crosses in Fig. $4 \mathrm{~b}$,

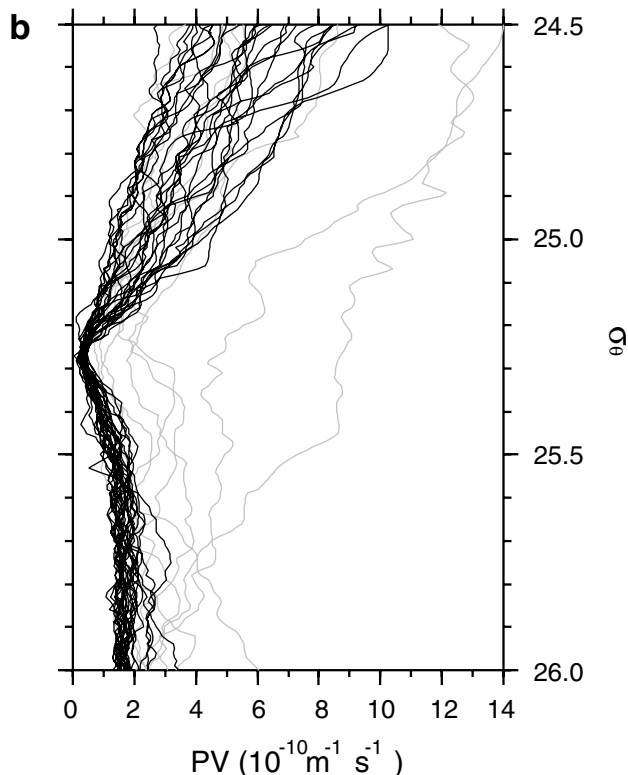

and others are indicated by gray lines. In Fig. $4 b$, stations are shown by crosses with the same colors as the profiles

d), which appears to be the condition of the existence of the AOU minima in Fig. 6a, rates of DO and AOU changes with respect to potential density were estimated as the differences between the mean values in early July and early December, divided by the time interval (Fig. 7). Taking into account the standard deviation representing the spatial variation, the rate of the decrease in DO based on the shipboard data is equivalent to or lower than that at the moored buoy station in most of the measured potential density range (vertical dashed line in Fig. 7a). Both the decreasing DO rate and increasing AOU rate diminish with potential density, from approximately 24.8 to $25.4 \sigma_{\theta}$. In other words, DO tends to decrease more slowly around the isopycnal of $25.3 \sigma_{\theta}$ than in the overlying layer. As a result, the secondary DO maximum is formed in the core layer of the STMW, which takes up oxygen from the atmosphere in winter.

Except for occasions on which the cyclonic eddy passed near the moored buoy station, potential density at $200 \mathrm{~m}$ (red dotted line in Fig. 3a) decreased from 25.3 to $25.0 \sigma_{\theta}$. Therefore, for most of the observation period, the sensor stayed above or near the layer of seasonal DO decrease where the AOU minima (the secondary DO maxima) were observed in December. Taking into account isopycnal lowering, or the DO decrease due to the slight decrease of potential density just above the secondary DO maxima, the decreasing rate of DO from the consumption of organic matter would be smaller than the present estimate. Sukigara et al. (2011) estimated a decreasing rate on the isopycnal of $25.15 \sigma_{\theta}$ in the STMW layer within an anticyclonic mesoscale eddy $\left(-0.229 \mu \mathrm{mol} \mathrm{kg}{ }^{-1}\right.$ day $\left.^{-1}\right)$, which is more rapid 

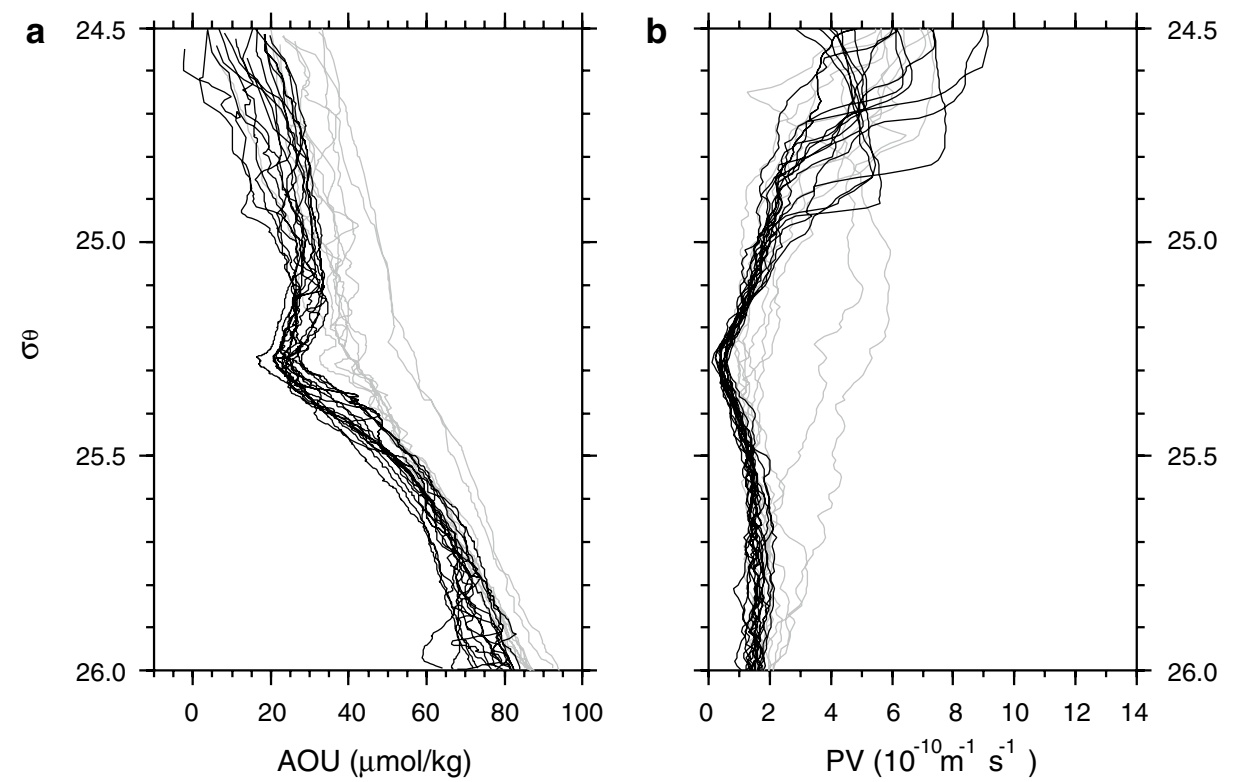

Fig. 6 Same as in Fig. 5, but for the stations in early December 2012 shown in Fig. 4d

Fig. 7 a Rate of DO change and $\mathbf{b}$ rate of AOU change in relation to $\sigma_{\theta}$ from early July through early December 2012. Mean values (thick solid line) and standard deviations (dotted lines) are based on data at stations with AOU smaller than $30 \mu \mathrm{mol} \mathrm{kg} \mathrm{kg}^{-1}$ on $25.3 \sigma_{\theta}$ surface (black crosses in Fig. 4b, d). In a, the rate of DO decrease at the moored buoy station is shown by a vertical dashed line to denote the measured potential density range
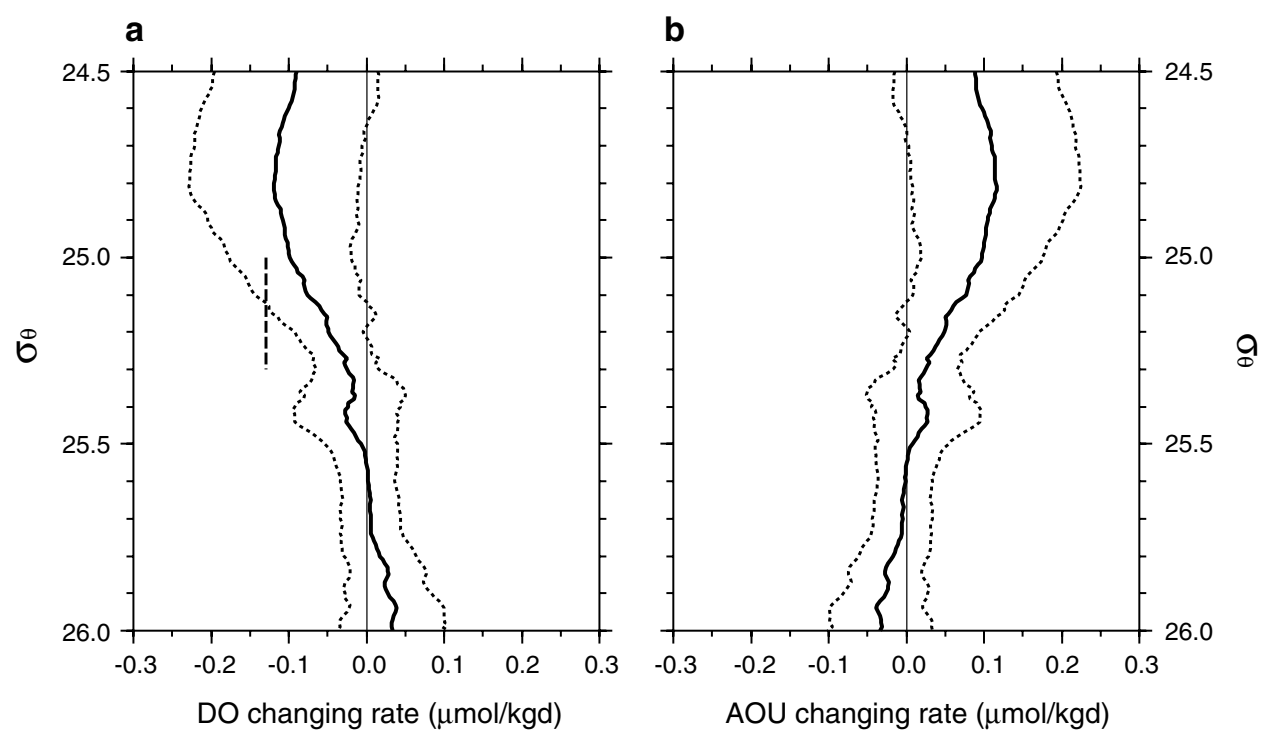

than the present estimates. The high rate of DO decrease is attributed to the abrupt decrease in DO by approximately $10 \mu \mathrm{mol} \mathrm{kg}^{-1}$ in late June 2006 (around Julian day 180); before the abrupt decrease, the decreasing rate was equivalent to present estimates.

During a 3-day period beginning January 8, 2013, DO at a depth of $200 \mathrm{~m}$ rose to approximately $220 \mu \mathrm{mol} \mathrm{kg}-1$. The water in the layer was nearly saturated $(\sim 94 \%)$ with oxygen. After the steep increase, DO at depth increased gradually until early March, reaching $228 \mu \mathrm{mol} \mathrm{kg}{ }^{-1}$. The rapid recovery to near oxygen saturation in early January and the subsequent gradual DO increase were associated with an abrupt decrease and a gradual increase in potential density (red dotted line in Fig. 3a). The rapid increase in DO likely marks the time when the local mixed layer extended to $200 \mathrm{~m}$ and the STMW began to ventilate. The subsequent gradual increase may reflect the uptake of oxygen from the atmosphere and/or biological production of oxygen.

\subsection{Cross-frontal subduction}

After mid-February 2013, the KE abruptly shifted southwestward (dashed contours in Fig. 1). Weekly SSH maps from February 6 to March 13, 2013, are shown in Fig. 8. 
a

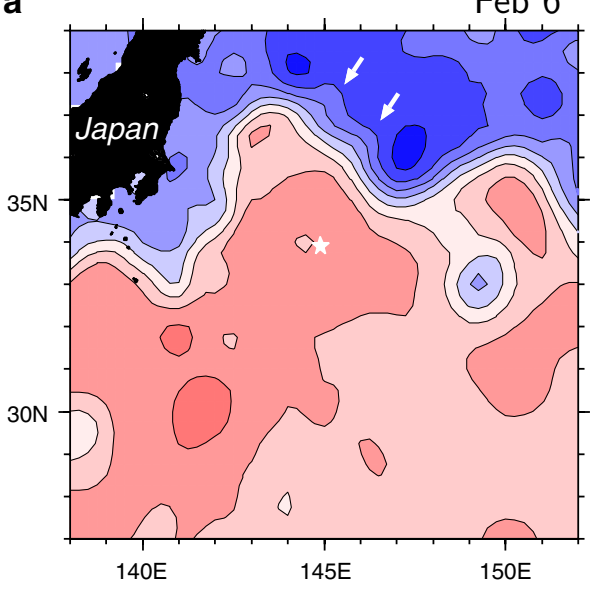

b

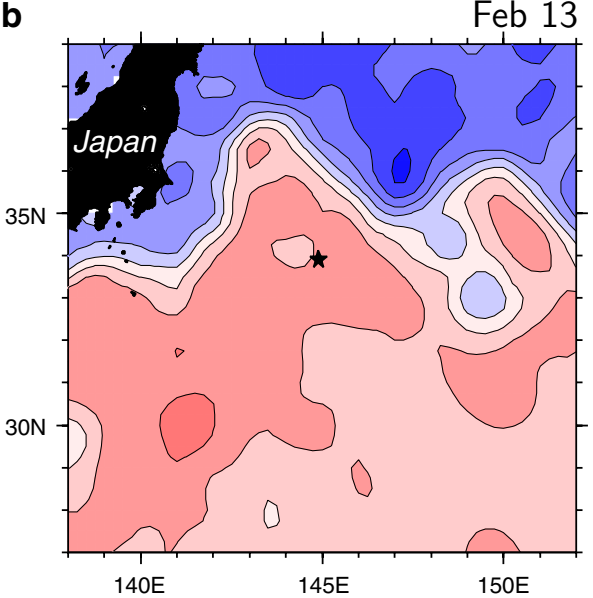

c

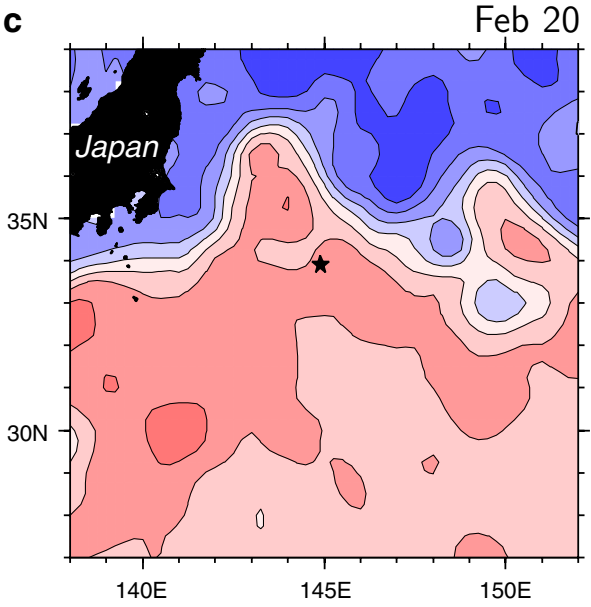

Fig. 8 Weekly absolute SSH $(\mathrm{cm})$ in the KE region from a February 6 to $\mathbf{f}$ March 13, 2013. Contour interval is $20 \mathrm{~cm}$. SSH data were derived from AVISO. Stars from a to e indicate location of the moored buoy station, and crosses in $\mathbf{f}$ show $\mathrm{CTDO}_{2}$ stations in

On February 6 (Fig. 8a), the KE jet protruded northward on mesoscale or smaller eddies in the upstream of the meander trough near $35.0^{\circ} \mathrm{N}, 146.2^{\circ} \mathrm{E}$ (indicated by white arrows in d
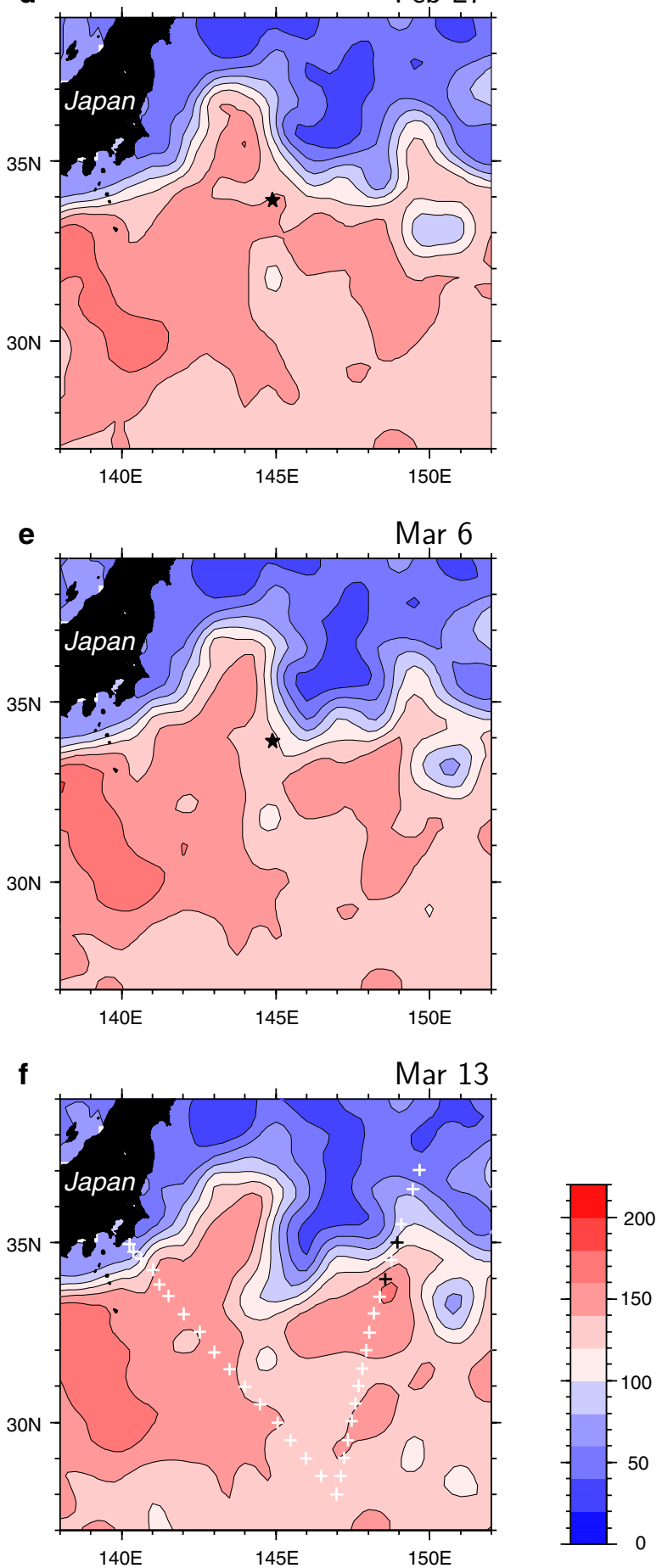

the mid-March 2013 cruise. Stations where subductions of high-DO waters were observed are black, and others are white. White arrows in a show mesoscale/submesoscale disturbances of the KE jet described in the text

Fig. 8a). Subsequently, the meander trough of the KE jet developed in mid to late February (Fig. 8b-d), and reached the buoy station in early March (Fig. 8e, f). 
This kind of meso- or submesoscale jet meandering induces a three-dimensional ageostrophic cross-frontal circulation and may cause subduction of surface mixed-layer water, as demonstrated in previous theoretical and numerical studies (e.g., Spall 1995; Yoshikawa et al. 2001, 2012). During the highly variable KE jet, the layered AOU structure (Fig. 3b) was significantly disturbed. At a depth of $600 \mathrm{~m}$ (blue solid line in Fig. 3a), a notably high DO, which twice exceeded $230 \mu \mathrm{mol} \mathrm{kg}{ }^{-1}$, was observed from February 12 to March 7, 2013. No significant change in potential density was observed on these occasions. Therefore, the high-DO signal did not originate from an anticyclonic mesoscale eddy that could lower the main pycnocline around a depth of $600 \mathrm{~m}$ but was likely related to the development of the KE meander.

The AOU value $\left(\sim 40 \mu \mathrm{mol} \mathrm{kg} \mathrm{kg}^{-1}\right)$ at a depth of $600 \mathrm{~m}$ (blue solid line in Fig. 3b) from February 12 to March 7, 2013, was equivalent to and sometimes slightly lower than the value at a depth of $400 \mathrm{~m}$ (green solid line). Judging from the differences in $\mathrm{DO}, \mathrm{AOU}$, and potential density between depths of 200 and $600 \mathrm{~m}$, the high-DO water with a potential density of approximately $26.4 \sigma_{\theta}$ at $600 \mathrm{~m}$ in the late winter was not outcropped near the buoy station. Therefore, it must have been subducted to the layer from north of the KE, where the outcropping of the isopycnal layer of $26.4 \sigma_{\theta}$ occurs (e.g., Suga et al. 2004).

Each of the high-DO signals continued for approximately 10 days. Considering that the mooring site was located on the southern flank of the KE, the long duration of the high-DO signals indicates that the intrusions may have been elongated in the direction of the current like filaments. Similar filament-like intrusions have been produced in numerical models of a zonal jet by Spall (1995), Yoshikawa et al. (2001, 2012), and others. Considering the speed of the eastward current observed on the southern flank of the KE between approximately 400 and $600 \mathrm{dbar}$ at the E-line $\left(\sim 30 \mathrm{~cm} \mathrm{~s}^{-1}\right)$, the filament length of the high-DO water (the product of the current speed and the duration of the high-DO signal) was estimated as $\sim 260 \mathrm{~km}$.

The eastward extension of the high-DO water from the time series at the buoy station is shown in Fig. 9a, b as sections of DO and AOU at the W-line and E-line in midMarch 2013, respectively. In the main pycnocline between 400 and 900 dbar (Fig. 9c), DO decreased sharply from 180 to $60 \mu \mathrm{mol} \mathrm{kg}{ }^{-1}$ (Fig. 9a). The layer of the sharp vertical DO gradient ascended northward across the KE jet at latitudes of approximately $34^{\circ} \mathrm{N}$ at the W-line and $35^{\circ} \mathrm{N}$ at the E-line. At the E-line (right panel in Fig. 9a), patchy mesoscale/submesoscale water masses characterized by DO higher than approximately $240 \mu \mathrm{mol} \mathrm{kg}{ }^{-1}$, which corresponded to AOU lower than approximately $50 \mu \mathrm{mol} \mathrm{\textrm {kg } ^ { - 1 }}$ (Fig. 9b), were found to intrude into the south of the KE (black crosses in Fig. 8f) along the slope of the main pycnocline between 26.1 and $26.6 \sigma_{\theta}$ (Fig. 9c). This intrusion at latitude $34^{\circ} \mathrm{N}$ was remarkably thick and extended from approximately 400 to $900 \mathrm{dbar}$. The maximal DO value of $285 \mu \mathrm{mol} \mathrm{kg}-1$ was found at a depth of approximately $800 \mathrm{dbar}$.

Note that the high-DO waters were accompanied by intrusions of low-salinity $(<34.0)$ waters (Fig. 9d). The base of the low-salinity water reached to approximately 1100 dbar, which was deeper than that of the high-DO (low-AOU) water. Much thicker water than expected from the DO (AOU) signature alone was involved in the crossfrontal subduction from the north of the KE. With this anomalously thick subduction in late winter, the waters fresher than 34.0 intruded into the layer below the isopycnal surface of $26.7 \sigma_{\theta}$. These are considered to be the Oyashio-derived waters as studied by Okuda et al. (2001) and Shimizu et al. (2004). Because this layer in the North Pacific is never exposed to the sea surface (Reid 1965), the intrusion into the layer deeper than 1000 dbar cannot be identified by either high DO (Fig. 9a) or low AOU (Fig. 9b).

To examine the properties of the subducted mesoscale water masses, we show the distributions of DO and AOU at the E-line in relation to potential density (Fig. 10a, b). The high-DO and low-AOU waters were subducted in a layer between the isopycnal surfaces of 26.1 and $26.6 \sigma_{\theta}$, and were accompanied by the low-salinity waters down to the isopycnal surface of $27.0 \sigma_{\theta}$ (Fig. 10c). In addition, we calculated PV using Eq. (1) (Figs. 9e, 10d). Anomalously low PV $\left(<1.5 \times 10^{-10} \mathrm{~m}^{-1} \mathrm{~s}^{-1}\right)$, or weak stratification, was associated with the high-DO waters (Figs. 9a, 10a).

The very thick subducted water (red line in Fig. 11a) consisted of several potential density layers around 26.1, 26.3, and $26.4 \sigma_{\theta}$ and was characterized by PV minima. This multiple-layer structure suggests simultaneous subduction of high-DO waters of different densities. Interestingly, potential densities in the minimal AOU layers (Fig. 11b) coincide with those in the minimal PV layers (Fig. 11a). The minimal AOU values were very low $(\sim 10 \mu$ mol kg-1). Therefore, the low-AOU water was likely subducted directly from the recently developed mixed layer.

Probably because of mixing with the surrounding water, the AOU around $26.4 \sigma_{\theta}$ at $35^{\circ} \mathrm{N}$ (blue line in Fig. $11 \mathrm{~b}$ ) was relatively high $\left(\sim 40 \mu \mathrm{mol} \mathrm{kg}{ }^{-1}\right)$ and was almost equivalent to that observed at the buoy station from February 12 to March 7, 2013 (blue solid line in Fig. 3b). The low-AOU (high-DO) signals at the buoy station in late winter might be evidence of detection of the lower part of the intruded water mass at $35^{\circ} \mathrm{N}$ on the E-line. On the basis of geostrophic velocity at the E-line calculated with a reference depth of 2000 dbar, the subducted low-AOU water masses may have been transported by the east-southeastward current at a velocity of approximately 20 to $40 \mathrm{~cm} \mathrm{~s}^{-1}$. The results 
Fig. 9 Sections of a DO $(\mu$ mol kg $\left.{ }^{-1}\right)$, b AOU ( $\mu \mathrm{mol} \mathrm{kg}{ }^{-1}$ ), c potential density $\sigma_{\theta}\left(\mathrm{kg} \mathrm{m}^{-3}\right)$, d salinity (psu), and e PV $\left(\mathrm{m}^{-1} \mathrm{~s}^{-1}\right)$ at the W-line (left panels) and E-line (right panels) in mid-March 2013. Contour intervals in $\mathbf{a}-\mathbf{e}$ are $20 \mu \mathrm{mol} \mathrm{kg}^{-1}$,

$20 \mu \mathrm{mol} \mathrm{kg}^{-1}, 0.2 \mathrm{~kg} \mathrm{~m}^{-3}$, 0.1 , and $0.5 \times 10^{-10} \mathrm{~m}^{-1} \mathrm{~s}^{-1}$, respectively. Inverted triangles indicate $\mathrm{CTDO}_{2}$ stations, and dashed lines show levels of 200 , 400, and $600 \mathrm{dbar}$
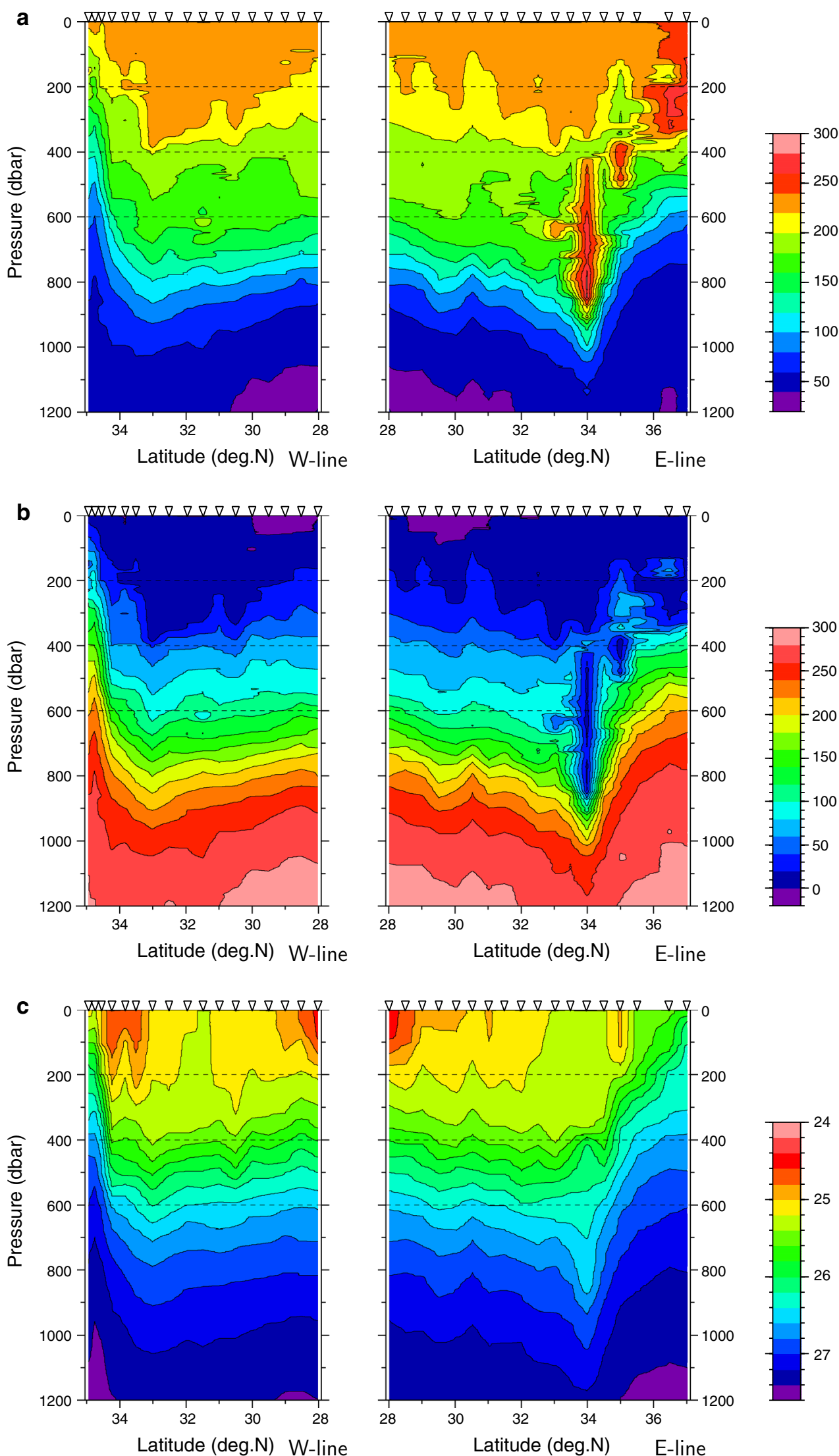
Fig. 9 continued
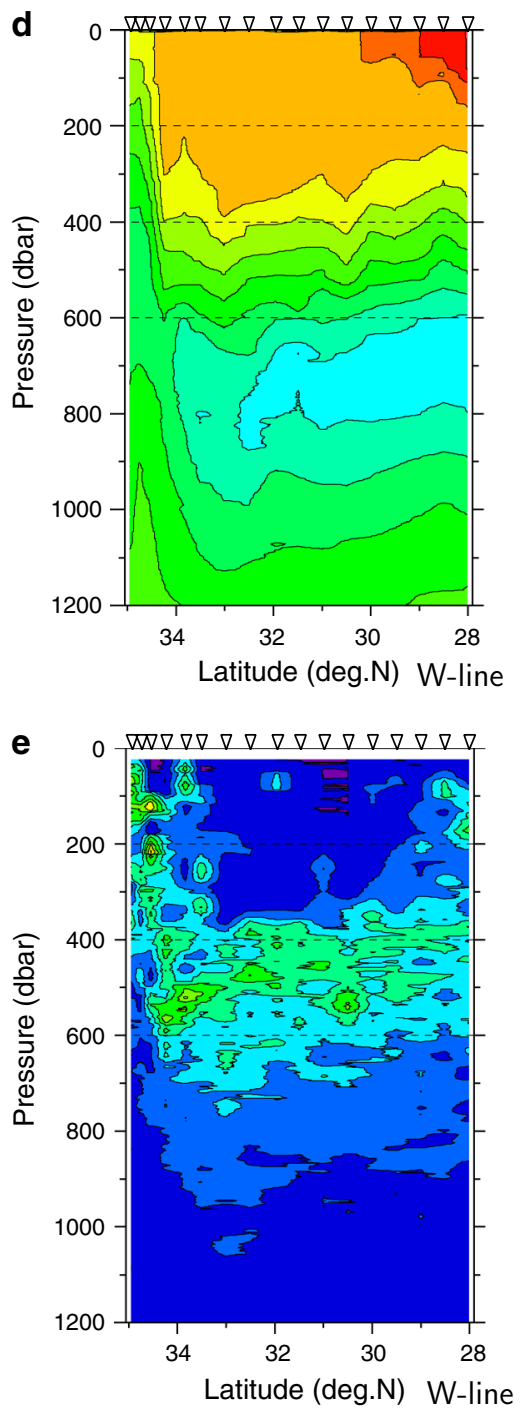
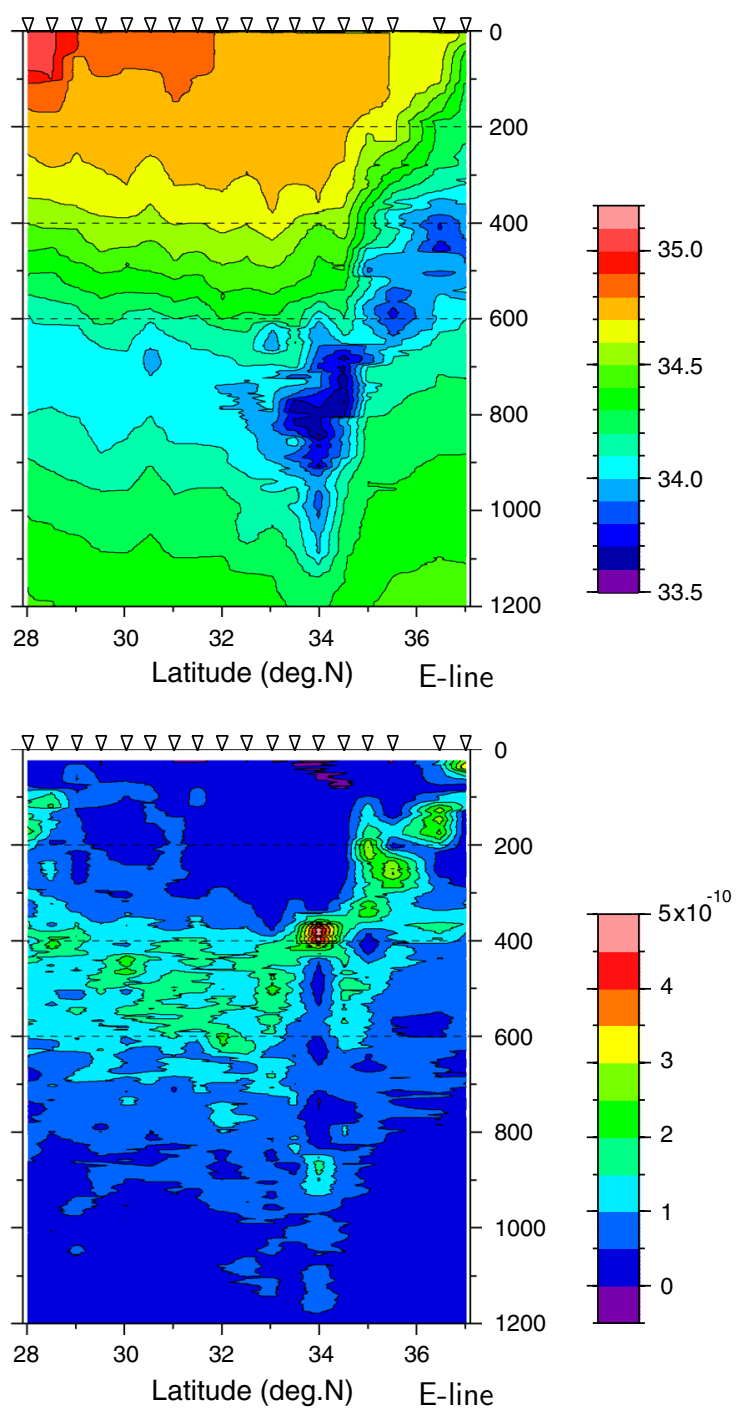

obtained from the analysis of shipboard $\mathrm{CTDO}_{2}$ data are consistent with the interpretation that the high-DO waters at the two stations on the E-line are related to the subduction event of the high-DO water detected at the buoy station from February 12 to March 7, 2013. On the other hand, it is possible that the high-DO waters at the E-line were subducted from different places on the KE jet at different times. Nevertheless, the spatiotemporal structure of mesoscale/ submesoscale subduction across the $\mathrm{KE}$ jet is revealed by the moored buoy and shipboard observations of DO.

At the W-line (left panels in Fig. 9), however, no significant traces of cross-frontal intrusions were observed in the sections of DO, AOU, potential density, salinity, or PV. The contrast between the E-line and W-line suggests that frontal mesoscale or smaller intrusions across the KE tend to occur in the downstream region of the KE meander crest near $143^{\circ} \mathrm{E}$; i.e., the upstream region of the meander trough around $147^{\circ} \mathrm{E}$ that is analogous to the characteristics of the southward onshore water outflow across the Kuroshio upstream of the large meander south of Japan (Nagano et al. 2010) and the mesoscale subduction across the Gulf Stream (Thomas and Joyce 2010).

\section{Summary and conclusion}

The Eulerian DO time series at depths of 200, 400, and $600 \mathrm{~m}$ were obtained over a period of approximately 10 months from June 2012 to March 2013 at the moored buoy station south of the KE jet $\left(33.9^{\circ} \mathrm{N}, 144.9^{\circ} \mathrm{E}\right)$. DO was considerably depressed due to isopycnal heaving of the cyclonic mesoscale eddies, as observed at depths of 400 and $600 \mathrm{~m}$ in June and at all depths in September 2012, and recovered after eddy passage. Ventilation of the STMW at a depth of $200 \mathrm{~m}$ near the secondary DO maximum (AOU minimum) layer was detected as a rapid increase in DO in January 2013 after a seasonal decrease at a rate of $-0.130 \pm 0.007 \mu \mathrm{mol} \mathrm{kg}{ }^{-1} \mathrm{day}^{-1}$ from July to December. 
Fig. 10 Distribution of a DO $\left(\mu \mathrm{mol} \mathrm{kg}^{-1}\right), \mathbf{b}$ AOU $(\mu$

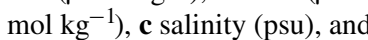
d PV $\left(\mathrm{m}^{-1} \mathrm{~s}^{-1}\right)$ at the E-line in mid-March 2013 in relation to potential density $\sigma_{\theta}$.

Contour intervals in $\mathbf{a}-\mathbf{d}$ are $20 \mu \mathrm{mol} \mathrm{kg}-1,20 \mu \mathrm{mol} \mathrm{kg} \mathrm{kg}^{-1}$, 0.1 , and $0.5 \times 10^{-10} \mathrm{~m}^{-1} \mathrm{~s}^{-1}$, respectively. Inverted triangles indicate $\mathrm{CTDO}_{2}$ stations. Red and blue triangles show the locations where vertical profiles of $\mathrm{PV}$ and $\mathrm{AOU}$, denoted by the same colors as in Fig. 11, were collected
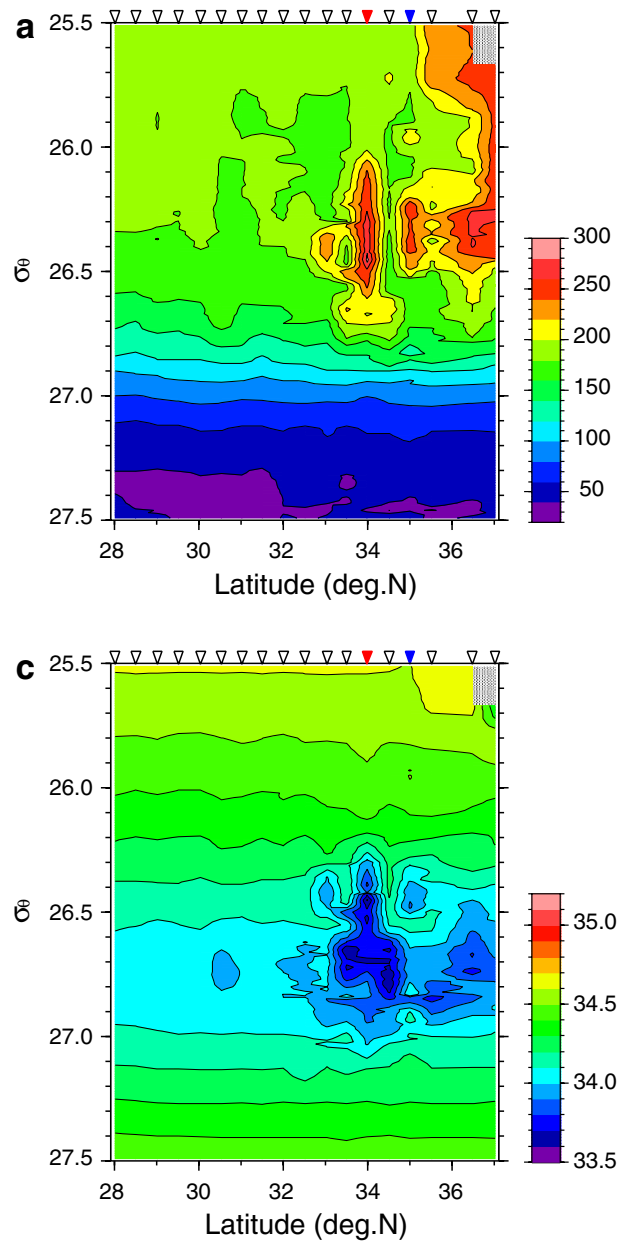
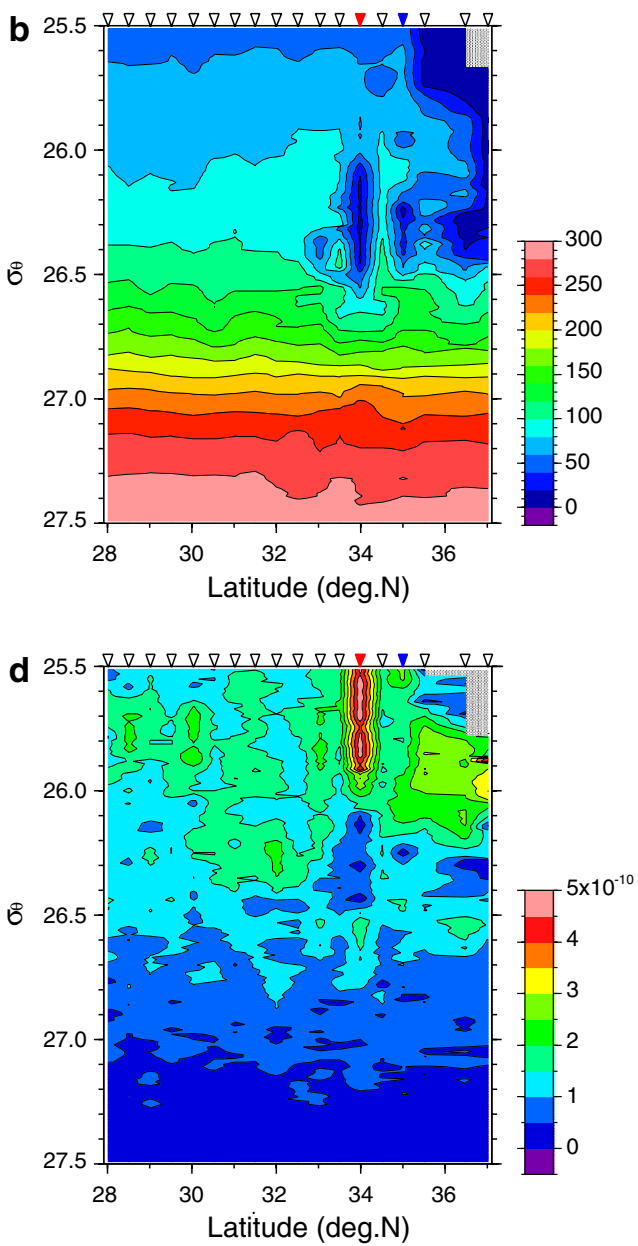

a

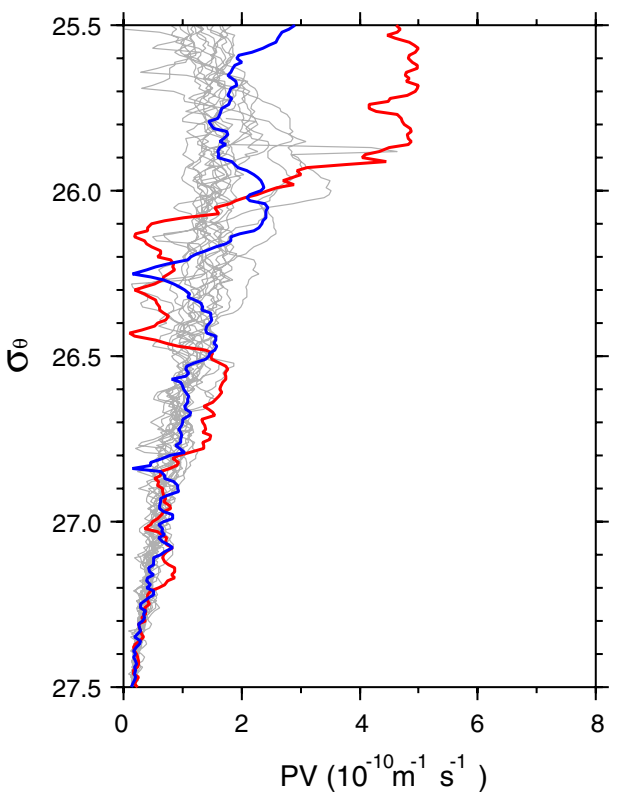

b

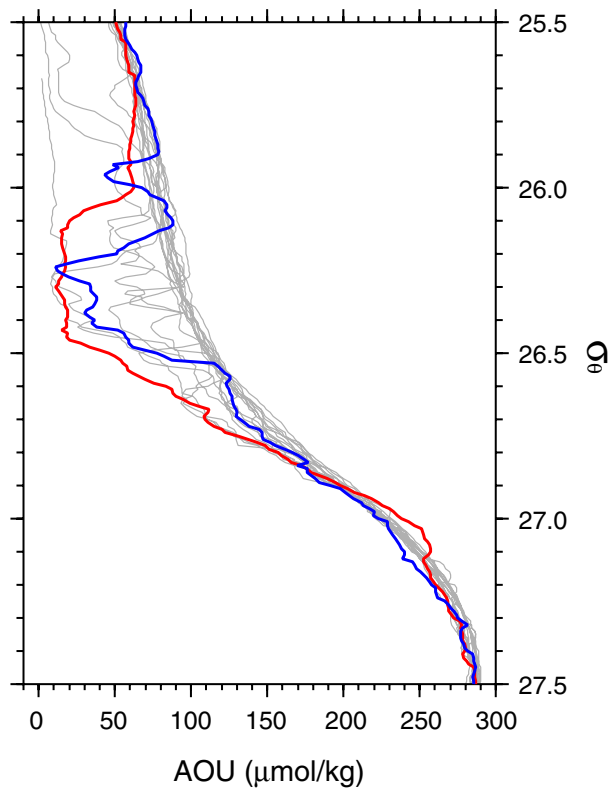

Fig. 11 Vertical profiles of $\mathbf{a} \mathrm{PV}$ and $\mathbf{b}$ AOU in relation to $\sigma_{\theta}$ at the E-line in mid-March 2013. Red and blue curves are profiles at the stations marked by inverted triangles of the same colors as in Fig. 10, and gray curves are profiles at other stations 
In addition, the DO time series suggests the cross-frontal transport of water masses: the lateral water transport (at $200 \mathrm{~m}$ in June 2012) due to the cyclonic mesoscale eddy pinched off from the KE and the southward mesoscale subduction of the high-DO water at $600 \mathrm{~m}$ from February 12 to March 7, 2013. The continuous high DO suggests that the subduction was elongated by approximately $260 \mathrm{~km}$ along the current on the southern flank of the KE. This filamentlike feature is a unique characteristic of mesoscale crossfrontal subduction, unlike the patchy water mass observed at a distance from the KE front by Oka et al. (2009).

A part of the subducted high-DO water was observed in the $\mathrm{CTDO}_{2}$ data collected in mid-March 2013 aboard the R/V Ryofu-maru in the downstream section of the KE meander crest (E-line). The water masses, whose maximal DO was $285 \mu \mathrm{mol} \mathrm{kg}{ }^{-1}$, were subducted in the layer between the isopycnal surfaces of 26.1 and $26.6 \sigma_{\theta}$ and vertically extended from approximately 400-900 dbar. The subducted water consisted of several water masses with different potential density values including 26.1, 26.3, and $26.4 \sigma_{\theta}$, which were associated with the DO maxima ( $>240 \mu \mathrm{mol} \mathrm{kg}{ }^{-1}$ ), and may have undergone different processes of formation and advection.

The subduction of high-DO and thick water masses indicated by the moored buoy and shipboard observations was associated with substantially lower PV $\left(<1.5 \times 10^{-10} \mathrm{~m}^{-1} \mathrm{~s}^{-1}\right)$, which is a typical signature of mode waters (e.g., Hanawa and Talley 2001). The subducted water masses likely contribute to the formation of a subsurface pycnostad structure in the North Pacific central mode water (Nakamura 1996; Suga et al. 1997; Oka and Qiu 2012). Simultaneously, low-salinity water fresher than 34.0 intrudes into the layer between 26.3 and $27.0 \sigma_{\theta}$ to a depth of approximately 1100 dbar. Such an intrusion may contribute to the formation of the North Pacific intermediate water (e.g., Shimizu et al. 2004). The variation in DO from the moored buoy observation and the hydrographic cross-sectional structure from shipboard observation provide evidence of meso- and submesoscale processes that transport water southward across the KE jet. This suggests that the near-surface water in areas north of the KE jet are directly subducted to the base of the main thermocline south of the jet, forming filament-like structures along the southern flank of the mesoscale/submesoscale meandering jet.

Mesoscale/submesoscale meanders at and around the $\mathrm{KE}$ jet are likely related to the generation of high-DO water subduction, as indicated in previous theoretical and numerical studies (e.g., Spall 1995; Yoshikawa et al. 2001, 2012). Similar submesoscale subduction of high-DO waters along the flank of the meandering KE were produced in an ecosystem model embedded in an ocean general circulation model with $1 / 30^{\circ}$ resolution (M. Nonaka and S. Hosoda, personal communication). Due to the limited coverage of the data used in this study, the general characteristics of the seasonal and year-to-year variation in mesoscale/submesoscale subduction and the subsequent behavior of subducted water cannot be addressed in this paper. Nevertheless, the present results will be invaluable in corroborating and improving high-resolution numerical models. In future studies, the seasonal and interannual variation in mesoscale/submesoscale water mass subduction will be examined using numerical models in addition to long-term buoy data and continuing Argo float data.

Acknowledgments The authors thank the captains, crews, technicians, and scientists on board the R/V Mirai (cruise number: MR1202, MR13-01) and the R/V Kaiyo (KY13-09) for deployment and recovery of the K-TRITON buoy and the emergency recovery of the drifting buoy, and those on board the R/V Ryofu-maru (RF1205, RF1208, and RF1302) for collecting $\mathrm{CTDO}_{2}$. The authors also thank Dr. H. Uchida (JAMSTEC) for providing equipment for calibration of RINKO I sensors, and Dr. K. Murakami (JMA) for calculation of rms errors of DO and salinity data collected by JMA. The authors are deeply grateful to a guest editor of this special issue, Dr. M. Nonaka (JAMSTEC), for his encouraging comments, and express gratitude to Prof. E. Oka (Atmosphere and Ocean Research Institute, The University of Tokyo) and anonymous reviewers for their constructive review comments. This work was supported in part by the Ministry of Education, Culture, Sports, Science and Technology (MEXT) Grant-in-Aid for Scientific Research on Innovative Areas (22106007) and Grant-inAid for Challenging Exploratory Research (26610148).

Open Access This article is distributed under the terms of the Creative Commons Attribution 4.0 International License (http://creativecommons.org/licenses/by/4.0/), which permits unrestricted use, distribution, and reproduction in any medium, provided you give appropriate credit to the original author(s) and the source, provide a link to the Creative Commons license, and indicate if changes were made.

\section{References}

Cronin MF, Meining C, Sabine CL, Ichikawa H, Tomita H (2008) Surface mooring network in the Kuroshio Extension. IEEE Syst J 2(3):424-430. doi:10.1109/JSYST.2008.925982

García HE, Gordon LI (1992) Oxygen solubility in seawater: better fitting equations. Limnol Oceanogr 37(6):1307-1312

Hanawa K, Talley LD (2001) Mode waters. In: Siedler H, Church J, Gould J (eds) Ocean circulation and climate: observing and modeling the global ocean. Academic Press, San Diego, pp 373-386

Ichikawa K, Imawaki S, Ishii H (1995) Comparison of surface velocities determined from altimeter and drifting buoy data. J Oceanogr 51:729-740

Measures CI, Cutter GA, Landing WM, Powell RT (2006) Hydrographic observations during the 2002 IOC Contaminant Baseline Survey in the western Pacific Ocean. Geochem Geophys Geosyst 7. doi:10.1029/2004GC000855

Nagano A, Uehara K, Suga T, Kawai Y, Ichikawa H, Cronin MF (2014) Origin of near-surface high-salinity water observed in the Kuroshio Extension region. J Oceanogr 70:389-403. doi:10.1007/s10872-014-0237-5

Nagano A, Ichikawa K, Ichikawa $H$, Tomita $H$, Tokinaga $H$, Konda M (2010) Stable volume and heat transports of the North Pacific 
subtropical gyre revealed by identifying the Kuroshio in synoptic hydrography south of Japan. J Geophys Res 115(C09002). doi:1 0.1029/2009JC005747

Nakamura H (1996) A pycnostad on the bottom of the ventilated portion in the central subtropical North Pacific: its distribution and formation. J Oceanogr 52:171-188

Nakamura H, Isobe A, Minobe S, Mitsudera H, Nonaka M, Suga T (2015) "Hot Spots" in the climate system-new developments in the extratropical ocean-atmosphere interaction research: a short review and an introduction. J Oceanogr 71:463-467. doi:10.1007/s10872-015-0321-5

Oka E, Qiu B (2012) Progress of North Pacific mode water research in the past decade. J Oceanogr 68:5-12. doi:10.1007/ s10872-011-0032-5

Oka E, Toyama K, Suga T (2009) Subduction of North Pacific central mode water associated with subsurface mesoscale eddy. Geophys Res Lett 38(L08607). doi:10.1029/2009GL037540

Okubo A (1958) The distribution of dissolved oxygen in the northwestern part of the North Pacific Ocean in the aspect of physical oceanography. Oceanogr Mag 10(1):137-156

Okuda K, Yasuda I, Hiroe Y, Shimizu Y (2001) Structure of subsurface intrusion of the Oyashio water into the Kuroshio Extension and formation process of the North Pacific intermediate water. $\mathrm{J}$ Oceanogr 57:121-140

Reid JL Jr (1965) Intermediate waters of the Pacific Ocean. The Johns Hopkins Oceanographic Studies, vol 2. The Johns Hopkins Press, Baltimore

Reid JL Jr (1962) Distribution of dissolved oxygen in the summer thermocline. J Mar Res 20(2):138-148

Reid JL (1997) On the total geostrophic circulation of the Pacific Ocean: flow patterns, tracers, and transports. Prog Oceanogr 39:263-352

Sarmiento JL, Gruber N (2006) Ocean biogeochemical dynamics. Princeton University Press, Princeton

Shimizu Y, Iwao T, Yasuda I, Ito S, Watanabe T, Uehara K, Shikama N, Nakano T (2004) Formation process of North Pacific intermediate water revealed by profiling floats set to drift on $26.7 \sigma_{\theta}$ isopycnal surface. J Oceanogr 60:453-462

Spall MA (1995) Frontogenesis, subduction, and cross-front exchange at upper ocean fronts. J Geophys Res 100(C2):2543-2557
Suess E (1980) Particulate organic carbon flux in the oceans-surface productivity and oxygen utilization. Nature 288:260-263

Suga T, Takei Y, Hanawa K (1997) Thermostad distribution in the North Pacific subtropical gyre: the central mode water and the subtropical mode water. J Phys Oceanogr 27(1):140-152

Suga T, Motoki K, Aoki Y, Macdonald A (2004) The North Pacific climatology of winter mixed layer and mode waters. J Phys Oceanogr 34:3-22

Suga T, Aoki Y, Saito H, Hanawa K (2008) Ventilation of the North Pacific subtropical pycnocline and mode water formation. Prog Oceanogr 77:285-297. doi:10.1016/j.pocean.2006.12.005

Sukigara C, Suga T, Saino T, Toyama K, Yanagimoto D, Hanawa K, Shikama N (2011) Biogeochemical evidence of large diapycnal diffusivity associated with the subtropical mode water of the North Pacific. J Oceanogr 67:77-85. doi:10.1007/ s10872-011-0008-5

Sukigara C, Suga T, Toyama K, Oka E (2014) Biogeochemical responses associated with the passage of a cyclonic eddy based on shipboard observations in the western North Pacific. J Oceanogr 70:435-445. doi:10.1007/s10872-014-0244-6

Taft B (1978) Structure of Kuroshio south of Japan. J Mar Res 36:77-117

Talley LD (1988) Potential vorticity distribution in the North Pacific. J Phys Oceanogr 18:89-106

Thomas LN, Joyce TM (2010) Subduction on the northern and southern flanks of the Gulf Stream. J Phys Oceanogr 40:429-438. doi: 10.1175/2009JPO4187.1

Ueki I, Fujii N, Masumoto Y, Mizuno K (2010) Data evaluation for a newly developed slack-line mooring buoy deployed in the eastern Indian Ocean. J Atmos Oceanic Technol 27:1195-1214. doi: 10.1175/2010JTECHO735.1

Yoshikawa Y, Akitomo K, Awaji T (2001) Formation process of intermediate water in baroclinic current under cooling. J Geophys Res 106(C1):1033-1051

Yoshikawa Y, Lee CM, Thomas LN (2012) The subpolar front of the Japan/East Sea. Part III: competing roles of frontal dynamics and atmospheric forcing in driving ageostrophic vertical circulation and subduction. J Phys Oceanogr 42:991-1011. doi:10.1175/ JPO-D-11-0154.1 